\title{
Green extracts from Coratina olive cultivar leaves: Antioxidant characterization and biological activity
}

\author{
Graziana Difonzo a, Annamaria Russo ${ }^{\mathrm{b}}$, Antonio Trani ${ }^{\mathrm{a}}$, Vito M. Paradiso ${ }^{\mathrm{a}}$, Marianna Ranieri ${ }^{\mathrm{b}}$, \\ Antonella Pasqualone ${ }^{\mathrm{a}}$, Carmine Summo ${ }^{\mathrm{a}}$, Grazia Tamma ${ }^{\mathrm{b}}$, Roccangelo Silletti ${ }^{\mathrm{a}}$, Francesco Caponio ${ }^{\mathrm{a}, *}$ \\ ${ }^{a}$ University of Bari Aldo Moro, Department of Soil, Plant and Food Sciences, Food Science and Technology Unit, Via Amendola, 165/A, I-70126 Bari, Italy \\ ${ }^{\mathrm{b}}$ University of Bari Aldo Moro, Department of Biosciences, Biotechnologies and Biopharmaceutics, Via Amendola, 165/A, I-70126 Bari, Italy
}

\section{A R T I C L E I N F O}

\section{Article history:}

Received 7 September 2016

Received in revised form 12 January 2017

Accepted 20 January 2017

\section{Keywords:}

Olive leaves

Antioxidant activity

Biophenols

Green extraction

Reactive oxygen species

\begin{abstract}
A B S T R A C T
Olive leaves and their extracts are associated with food preservation and health, and are used in folk medicine to treat several diseases, mainly because of their polyphenols. In this investigation polyphenols were extracted from olive leaves using green solvents and evaluated the antioxidant activity of the extracts. Polyphenols were extracted from fresh, freeze-dried, and hot air-dried leaves using either ethanol/water mixtures (70:30, 30:70, v/v) or water alone. Antioxidant activity was assessed in bronchial epithelial NCI-H292 cells by measuring reactive oxygen species (ROS) and in vegetable oil by measuring oxygen consumption. Results showed that extracts with a good antioxidant activity could be obtained when leaves were pre-treated by hot air-drying. The use of water alone as the extraction solvent gave results comparable to those obtained with ethanol/water $(30: 70, \mathrm{v} / \mathrm{v})$. These extracts were particularly rich in oleuropein, and had anti-ROS effects in NCI-H292 cells and antioxidant activity in vegetable oil.
\end{abstract}

(ㄷ) 2017 Elsevier Ltd. All rights reserved.

\section{Introduction}

Olive leaves and their extracts, have been associated with health for many centuries and are used in folk medicine to treat several pathologic conditions (de Bock et al., 2013; Sato et al., 2007). More recently, their use has been proposed for food preservation (Hayes, Stepanyan, Allen, O'Grady, \& Kerry, 2010). Harvested olives are accompanied by approximately 6\% of leaves, and annual world olive production exceeds 18 million tons (average 2006-2013) (United Nations Food and Agriculture Organization - Statistics Division, 2016). Olive trees are predominantly grown in the Mediterranean region, characterized by

\footnotetext{
Abbreviations: ABTS, 2,2'-Azino-bis(3-ethylbenzothiazoline-6-sulphonic acid) diammonium salt; BHA, butylated hydroxyanisole; BHT, butylated hydroxytoluene; CTR, control; DPPH, 2,2-diphenyl-1-picrylhydrazyl; Eth, ethanol; F, fresh; FD, freeze dried; HD, hot air-dried; ROS, reactive oxygen species; TBHP, tertbutylhydroperoxide; TPC, total phenol content; TE, Trolox equivalents; TEAC, Trolox equivalent antioxidant capacity; Trolox, ( \pm )-6-hydroxy-2,5,7,8-tetramethyl chromane-2-carboxylic acid; UHPLC-ESI-MS/MS, ultra-high performance liquid chromatography electrospray ionization tandem mass spectrometry.

* Corresponding author at: Università degli Studi di Bari Aldo Moro, DiSSPA, Sezione di Scienze e Tecnologie Alimentari, Via Amendola 165/a, I-70126 Bari, Italy.

E-mail address: francesco.caponio@uniba.it (F. Caponio).
}

extended periods of sunlight and high rates of pathogen and insect attack. To combat these stressors, olive trees synthesize large volumes of polyphenols, which are largely stored in their thick leaves (Boss, Bishop, Marlow, Barnett, \& Ferguson, 2016).

Several studies have involved extraction methods of bioactive compounds from fresh or dehydrated olive leaves: (i) conventional extraction by maceration (Rahmanian, Jafari, \& Wani, 2015), (ii) ultrasound-assisted extraction (Ahmad-Qasem et al., 2013; Japón-Luján, Luque-Rodríguez, \& Luque de Castro, 2006; Rahmanian et al., 2015) and microwave-assisted extraction (Rahmanian et al., 2015; Sánchez-Ávila, Priego-Capote, RuizJiménez, \& de Castro, 2009; Taamalli et al., 2012), and (iii) supercritical fluid extraction (Le Floch, Tena, Ríos, \& Valcárcel, 1998). Conventional extraction has some major drawbacks, such as insufficient recovery of extracts and long extraction times, and intensive heating and/or mixing result in high levels of energy consumption (Rombaut, Tixier, Bily, \& Chemat, 2014). Of the different nonconventional techniques, ultrasound-assisted extraction is considered one of the most interesting methods to increase the amount of compounds extracted from vegetal materials (Rombaut et al., 2014; Vilkhu, Mawson, Simons, \& Bates, 2008). Ultrasoundassisted extraction uses cheaper equipment than other extraction 
techniques, such as microwave-assisted extraction, and is much easier (Wang \& Weller, 2006; Zhang, Yang, \& Wang, 2011). It is a simple, efficient and inexpensive procedure with the potential for use on an industrial scale (Ahmad-Qasem et al., 2013; Huang, Xue, Niu, Jia, \& Wang, 2009).

Ultrasound-assisted extraction of bioactive compounds from olive leaves requires a suitable solvent, such as methanol, acetone, ethyl acetate, and ethanol, generally used in water mixtures (Ahmad-Qasem et al., 2013; Lee et al., 2009; Rahmanian et al., 2015; Zhang, Yang, Zhao, \& Wang, 2009). Solvents used in the chemical industry have a negative impact on the environment and also on costs, safety and health (Capello, Fischer, \& Hungerbühler, 2007). Methanol, acetone, and ethyl acetate have a negative impact on health and the environment, therefore, when the extracts are used in food and pharmaceutical applications, water has been recommended as an extraction solvent (Ghoreishi \& Shahrestani, 2009), because it is cheap and environmentally friendly (Shalmashi, Abedi, Golmohammad, \& Eikani, 2010), although its use is limited due to poor extraction efficiency at low temperatures (Ju \& Howard, 2005; Rahmanian et al., 2015).

Polyphenols are the most abundant molecules in the bioactive profile of olive leaves. Specifically, the secoiridoid oleuropein is the main compound together with other secoiridoids derived from tyrosol structure and flavonoids (Benavente-García, Castillo, Lorente, Ortuño, \& Del Rio, 2000). These compounds account for the antioxidant and antimicrobial activities of olive leaf extracts, and could make olive leaf extracts suitable for use in the food industry as natural preservatives (Rahmanian et al., 2015). Epidemiological studies have shown the significant influence of environmental factors, lifestyle and diet on both the insurgence and prevention of pathologies associated with oxidative damage, such as cardiovascular diseases, diabetes, neurodegenerative conditions and cancers (Bassani et al., 2016). The use of BHT (butylated hydroxytoluene) or BHA (butylated hydroxyanisole) in food has been reduced due to their suspected carcinogenic role and to general consumer rejection of synthetic food additives. This means that there is great interest in substituting these synthetic compounds with natural antioxidants, and olive leaves have potential for this use, since they contain high levels of antioxidant compounds (Erbay \& Icier, 2010).

Interestingly, it has been reported that the properties of olive leaf extracts include radio-protective (Castillo, Alcaraz, \& Benavente-García, 2010) and anti-proliferative effects on leukaemia cells by inducing apoptosis (Abaza et al., 2007; Samet, Han, Jlaiel, Sayadi, \& Isoda, 2014), in addition to cytotoxic activity on human breast cancer cells (Fu et al., 2010; Taamalli et al., 2012), and improvement of gentamicin nephrotoxicity (Tavafi, Ahmadvand, \& Toolabi, 2012), although the molecular mechanisms of action and health potential of these bioactive compounds require further investigation. In particular, oleuropein can be considered a functional food ingredient, and several health-promoting effects of oleuropein were recently reported in both in vitro and in vivo studies (van der Stelt et al., 2015). Many studies indicate the key role of reactive oxygen species (ROS) in cellular physiology, and how these can react with DNA, proteins or lipids to alter their normal functions (Tamma \& Valenti, 2016). The modification induced in redox homeostasis and the production of free radicals contributes to the pathogenesis of several diseases, such as asthma and chronic obstructive pulmonary diseases (COPD) (Lee \& Yang, 2012).

The goals of this study were as follows: (i) to develop a green extraction method by finding the optimal combination between drying and solvent use to obtain phenolic extracts; (ii) to evaluate the antioxidant activity of olive leaf extracts using a multidisciplinary approach.

\section{Materials and methods}

\subsection{Materials and reagents}

Olive leaves (Olea europaea L., cultivar Coratina) were collected on an olive grove in Acquaviva delle Fonti (Bari, Italy) in February and March 2016, stored at $4{ }^{\circ} \mathrm{C}$ and processed in less than $24 \mathrm{~h}$. Green olive fruits (Olea europaea L., cultivar Coratina) were collected in the grove aforementioned in November 2016. Olive oil was purchased from local retailers settled in Bari (Italy). The corresponding purified olive oil was obtained according to the method described in Paradiso, Gomes, Nasti, Caponio, and Summo (2010).

The reagents used were Folin-Ciocalteu reagent; ABTS (2,2'-azi no-bis(3-ethylbenzothiazoline-6-sulphonic acid) diammonium salt); DPPH (2,2-diphenyl-1-picrylhydrazyl); dihydrorhodamine123; Trolox (( \pm )-6-hydroxy-2,5,7,8-tetramethylchromane-2-car boxylic acid); TBHP (tert-butylhydroperoxide) were purchased from Sigma-Aldrich (Milan, Italy), Milli-Q ${ }^{\circledR}$ water (Merck, Darmastdt, Germany); RPMI 1640 and phosphate-buffered saline (PBS) were purchased from Euroclone (Pero, Italy).

\subsection{Bioactive compounds extraction}

Three different lots of olive leaves were considered. For each lot, three different leaves samples were considered: (i) fresh leaves (F) having a mean moisture content, determined with thermobalance (Radwag, Radom, Poland), equal to $45.66 \%$; (ii) freeze-dried leaves (FD) at $-50^{\circ} \mathrm{C}$ and a pressure of $0.08 \mathrm{mbar}$ (A. De Mori, Milan, Italy) for $36 \mathrm{~h}$ to obtain a moisture content $<1 \%$; (iii) hot air-dried leaves (HD) at $120^{\circ} \mathrm{C}$ for $8 \mathrm{~min}$ in a ventilated oven (Argolab, Carpi, Italy) to obtain a moisture content $<1 \%$.

Polyphenol extraction from the leaves (F, FD, and HD) was carried out according to Ahmad-Qasem, Barrajón-Catalán, Micol, Mulet, and García-Pérez (2013) with some modifications. In particular, after milling with a blender (Waring-Commercial, Torrington, CT, USA), solvent was added (ratio $1 / 20, w / v$ ) and then subjected to ultrasound (CEIA, Viciomaggio, Italy) three times, for $30 \mathrm{~min}$ at $35 \pm 5^{\circ} \mathrm{C}$ each time. Finally, the extracts were filtered through Whatman (GE Healthcare, Milan, Italy) filter paper $\left(67 \mathrm{~g} \mathrm{~m}^{-2}\right)$, lyophilized and stored at $-20^{\circ} \mathrm{C}$. For each leaf typology three different extraction solvent were used: (i) ethanol/water 70:30 (Eth-70, $\mathrm{v} / \mathrm{v})$; (ii) ethanol/water 30:70 (Eth-30, v/v); (iii) only water (Eth-0). The obtained extracts, dissolved in acetonitrile/water solution $(70: 30, v / v)$ at concentration of $10 \mathrm{mg} \mathrm{mL}^{-1}$, were filtered with nylon filters of $0.45 \mu \mathrm{m}$ (Sigma Aldrich) and used for antioxidant activity evaluation tests and chemical characterization.

Polyphenol extraction from the fresh olive fruits was performed as reported by Xie, Huang, Zhang, and Zhang (2015) with some modifications. Approximately $1 \mathrm{~g}$ of homogenized sample was added to $10 \mathrm{~mL}$ of ethanol/water $(70: 30, \mathrm{v} / \mathrm{v})$ for $10 \mathrm{~min}$ subjected to ultrasound treatment. The hydroalcoholic phases were collected and subjected to centrifugation (Thermo Fisher Scientific, Osterode am Harz, Germany) at room temperature at $3950 \mathrm{~g} \mathrm{~min}^{-1}$ and successively $8900 \mathrm{~g} \mathrm{~min}^{-1}$ each for $4 \mathrm{~min}$; the extracts were then filtered through nylon filters (pore size $0.45 \mu \mathrm{m}$ ), lyophilized and stored at $-20^{\circ} \mathrm{C}$.

\subsection{Extracts characterization}

The total phenols content was determined according to the Folin-Ciocalteu method. To $100 \mu \mathrm{L}$ of appropriately diluted extract, was added $100 \mu \mathrm{L}$ of Folin-Ciocalteu reagent. After $4 \mathrm{~min}, 800 \mu \mathrm{L}$ of $5 \% \mathrm{Na}_{2} \mathrm{CO}_{3}$ were added and then incubated at $40{ }^{\circ} \mathrm{C}$ for $20 \mathrm{~min}$. The absorbance was read at $750 \mathrm{~nm}$ (Paradiso, Clemente, Summo, Pasqualone, \& Caponio, 2016). The results were expressed as mg 
of gallic acid equivalents $\mathrm{g}^{-1}$ of dry weight sample. Each sample was analyzed in triplicate.

The ultra-high performance liquid chromatography electrospray ionization tandem mass spectrometry (UHPLC-ESI-MS/MS, Thermo Fischer Scientific, Waltham, MA, USA) analysis was performed by using the UHPLC Dionex Ultimate 3000 system (LPG-3400 RS quaternary pump, WPS-3000 TRS autosampler, TCC-3000 RS column oven and PDA), coupled with the HESI-II probe and the LTQ Velos Pro ion trap mass spectrometer (Thermo Fischer Scientific). The separation of phenolic compounds was performed on Hipersyl Gold aQ $\mathrm{C}_{18}, 1.9 \mu \mathrm{m}$ particle size, i.d. $2.1 \mathrm{~mm} \times 100 \mathrm{~mm}$ length (Waters, Milford, MA, USA) maintained at $30^{\circ} \mathrm{C}$ using a mobile phase consisting of (A) water/formic acid (99.9:0.1, v/v) and (B) methanol/acetonitrile/formic acid (94.9:5:0.1, v/v/v), at the constant flow rate of $0.3 \mathrm{~mL} \mathrm{~min}^{-1}$. The gradient program of solvent $A$ was as follows: $0-1$ min isocratic 95\%; $1-18$ min increases to $55 \% ; 18-20$ min decreases to 65 . The UV absorbance was acquired at $280 \mathrm{~nm}$. The MS conditions were: capillary temperature $320^{\circ} \mathrm{C}$; source heater temperature $280^{\circ} \mathrm{C}$; nebulizer gas $\mathrm{N}_{2}$; sheath gas flow 30 psi; auxiliary gas flow 7 arbitrary units; capillary voltage -2800 V, S-Lens RF Level $60 \%$. Data were acquired in negative ionization mode. Samples were analyzed with two methods. A full scan method from 100 to $900 \mathrm{~m} / \mathrm{z}$ was used to quantify the phenolic compounds by the extraction of molecular ion signals in post-acquisition. A data-dependent experiment was used to collect $\mathrm{MS}^{2}$ data in order to identify the eluted compounds. The data-dependent settings were: full scan from 250 to $1200 \mathrm{~m} / \mathrm{z}$, activation level 65,000 counts, isolation width $2 \mathrm{Da}$, default charge state 2, CID energy 35. All data were acquired and processed using Xcalibur v.2 (Thermo Fischer Scientific). The tentative identification of phenolic compounds was achieved by combining elution times, molecular ions, MS/MS fragmentation patterns and literature data (Herrero et al., 2011; Kontogianni et al., 2013). A calibration curve was set up by using luteolin7-glucoside as external standard in the calibration range 0.1$5 \mu \mathrm{g} \mathrm{mL}{ }^{-1}$, obtaining a $R^{2}$ of 0.995 . The regression equation was:

$\left[\mu \mathrm{g} * \mathrm{~mL}^{-1}\right]=2.5 * 10^{-7} *$ Area $_{i}$

The results are expressed as $\mathrm{mg} \mathrm{g}^{-1}$ extract of luteolin-7glucoside equivalents. Each sample was analyzed in triplicate.

\subsection{Antioxidant activity evaluation}

Extracts were analyzed for their capacity to scavenge the stable DPPH radical. The assay was performed according to BrandWilliams, Cuvelier, and Berset (1995) with modifications, by preparing a solution of DPPH $0.08 \mathrm{mM}$ in ethanol. In cuvettes for spectrophotometry, $50 \mu \mathrm{L}$ of each sample were added to $950 \mu \mathrm{L}$ of DPPH solution. After 30 min in the dark, the decrease of absorbance was read at $517 \mathrm{~nm}$ using a Cary 60 Agilent spectrophotometer (Cernusco, Milan, Italy). The results were expressed in $\mu$ mol Trolox equivalents (TE) $\mathrm{g}^{-1}$ dry weight. Each sample was analyzed in triplicate.

The ABTS-TEAC assay was carried out as described by Re et al. (1999), based on the capacity of a sample to inhibit the ABTS radical $\left(\mathrm{ABTS}^{+}\right)$compared with a reference antioxidant standard (Trolox). The $\mathrm{ABTS}^{+}$radical was generated by chemical reaction with potassium persulfate $\left(\mathrm{K}_{2} \mathrm{~S}_{2} \mathrm{O}_{8}\right)$. For this purpose, $25 \mathrm{~mL}$ of ABTS ( $7 \mathrm{mM}$ in $\mathrm{H}_{2} \mathrm{O}$ ) was spiked with $440 \mu \mathrm{L}$ of $\mathrm{K}_{2} \mathrm{~S}_{2} \mathrm{O}_{8}(140 \mathrm{mM})$ and allowed to stand in darkness at room temperature for $12-16 \mathrm{~h}$ (the time required for formation of the radical). The working solution was prepared by taking a volume of the previous solution and diluting it in ethanol until its absorbance at $\lambda=734 \mathrm{~nm}$ was $0.70 \pm 0.02$ (Zulueta, Esteve, \& Frígola, 2009). A Cary 60 Agilent spectrophotometer was used. The reaction took place directly in the measuring cuvette: $50 \mu \mathrm{L}$ of each sample were added to $950 \mu \mathrm{L}$ of final $\mathrm{ABTS}^{+}$solution. After $8 \mathrm{~min}$ the decrease of absorbance was measured at $734 \mathrm{~nm}$. The results are expressed in $\mu \mathrm{mol}$ $\mathrm{TE}^{-1}$ dry weight. Each sample was analyzed in triplicate.

RapidOxy (Anton Paar, Blankenfelde-Mahlow, Germany) is a microprocessor-controlled automatic testing device for quick measures of the oxidative stability of lipid matrices, in response to forced oxidation with increase of temperature and $\mathrm{O}_{2}$ pressure. The induction time of the sample is measured as the time needed for a $10 \%$ drop of the oxygen pressure. The set parameters were the following: $\mathrm{T}=140{ }^{\circ} \mathrm{C}, \mathrm{P}=700 \mathrm{kPa}$. The obtained extracts were added at two different concentrations $\left(500 \mathrm{mg} \mathrm{kg}^{-1}\right.$ and $1000 \mathrm{mg} \mathrm{kg}^{-1}$ ) both to commercial olive oil and the corresponding purified olive oil. Each sample was analyzed in duplicate.

\subsection{ROS measurement}

The bronchiolar epithelial cells, NCI-H292, were used as experimental model to detect changes in intracellular ROS content. NCIH292 cells (from ATCC) were grown in Advanced RPMI 1640 Media supplemented with $10 \%(\mathrm{v} / \mathrm{v})$ fetal bovine serum and 100 i.u. $\mathrm{mL}^{-1}$ penicillin, $100 \mu \mathrm{g} \mathrm{mL}^{-1}$ streptomycin at $37^{\circ} \mathrm{C}$ with $5 \% \mathrm{CO}_{2}$. NCIH292 cells were seeded on 12 well cell culture cluster.

To evaluate the antioxidant effect of olive leaves extract, intracellular ROS level were measured as already described in Tamma et al. (2014). Briefly, cells were left untreated (CTR) or incubated with the oxidant named tert-butylhydroperoxide (TBHP) as positive control. Alternatively, cells were incubated for $24 \mathrm{~h}$ with the dried olive leaf extracts $\left(0.1 \mathrm{mg} \mathrm{mL}^{-1} ; \quad 0.01 \mathrm{mg} \mathrm{mL}^{-1}\right.$; $0.001 \mathrm{mg} \mathrm{mL}^{-1}$ ), obtained by different green extraction methods. After treatments, cells were incubated with dihydrorhodamine$123(10 \mu \mathrm{M})$ in PBS for $30 \mathrm{~min}$ at $37^{\circ} \mathrm{C}, 5 \% \mathrm{CO}_{2}$ and recovered in complete medium for $30 \mathrm{~min}$ in the absence (CTR and positive CTR) or in the presence of olive leaf extracts. In the last $15 \mathrm{~min}$ of recovery, cells were untreated or treated with TBHP ( $1 \mathrm{mM}$ for $15 \mathrm{~min}$ ) and then lysed in a buffer containing 1\% Triton X-100 $150 \mathrm{mM} \mathrm{NaCl}, 25 \mathrm{mM}$ Hepes ( $\mathrm{pH}$ 7.4). Lysates were analyzed by RF-5301PC fluorimeter (Shimadzu, Kyoto, Japan) equipped with Cary Eclipse fluorescent software (excitation wavelength: $512 \mathrm{~nm}$, emission wavelength: $530 \mathrm{~nm}$ ).

\subsection{Statistical analysis}

Analysis of variance and multivariate analysis of variance (ANOVA and MANOVA) and Tukey's test were carried out on the experimental data by the Minitab Statystical Software (Minitab Inc., State College, PA, USA). Dunnett's test was carried out by Graphpad Prism Software (GraphPad Software Inc., La Jolla, CA, USA).

\section{Results and discussion}

\subsection{Characterization of extracts and measurement of antioxidant activity}

The identification data of polyphenols contained in the extracts are reported in Table 1. By combining the information provided by MS/MS experiments and $\lambda_{\max }$, it was possible to identify the polyphenols in accordance with Herrero et al. (2011) and Kontogianni et al. (2013). In particular, we identified secoiridoids, flavonoids, tyrosol-related compounds and hydroxycinnamic acid derivatives (Table 1). Coumaric glucoside, coumaric diglucoside and ferulic diglucoside were only tentatively identified by considering the MS ${ }^{2}$ signals and UV spectra. In fact, the $\mathrm{m} / \mathrm{z} 505.2$ detected at 4.37 min produced the fragments 161 and 179 in 
Table 1

Identification data of polyphenol compounds of olive leaves extract performed by UHPLC-ESI-MS/MS system.

\begin{tabular}{|c|c|c|c|c|}
\hline $\mathrm{RT}(\mathrm{min})$ & {$[\mathrm{M}-\mathrm{H}]^{-}$} & Name & $\lambda_{\max }$ & Main fragments $^{\mathrm{a}}$ \\
\hline 2.3 & 315.2 & Hydroxytyrosol glucoside & 280 & $153(100)-135(25)-123(9)$ \\
\hline 2.4 & 389.1 & Oleoside & 220 & $227(100)-209(11)-183(96)-165(48)-121(15)$ \\
\hline 3.36 & 137.0 & Tyrosol & 280 & 123 \\
\hline 3.36 & 389.1 & Secologanoside $(1)^{\mathrm{b}}$ & 232 & 345 \\
\hline 4.37 & 505.2 & Coumaric diglucoside ${ }^{*}$ & 292 & $161(100)-179(67)-221(17)-251(34)-281(55)$ \\
\hline 5.5 & 389.0 & Secologanoside $(2)^{\mathrm{b}}$ & $230-334$ & $345(100)-209(22)-165(13)-121(10)$ \\
\hline 5.5 & 489.2 & Coumaric glucoside & 276 & $265(59)-235(29)-205(16)-163(100)$ \\
\hline 6.55 & 519.3 & Ferulic diglucoside ${ }^{*}$ & $292-326$ & $325(35)-295(25)-265(18)-235(38)-193(100)$ \\
\hline 9.1 & 609.2 & Luteolin diglucoside & $\dagger$ & 447 \\
\hline 10.2 & 555.3 & 10-Hydroxyoleuropein & $\dagger$ & $537(100)-403(45)-323(17)-223(12)$ \\
\hline 10.38 & 623.2 & Verbascoside & $292-332$ & 461 \\
\hline 12.38 & 377.2 & Oleuropein aglycon ${ }^{b}$ & $\dagger$ & $346(23)-307(100)-275(85)$ \\
\hline 11.4 & 447.2 & Luteolin-7-glucoside (1) & $\dagger$ & 285 \\
\hline 11.5 & 593.0 & Luteolin rutinoside & $\dagger$ & 285 \\
\hline 11.83 & 609.0 & Rutin & $\dagger$ & 301 \\
\hline 12.4 & 539.2 & Oleuropein & $234-282$ & $377(100)-345(16)-307(75)-275(72)$ \\
\hline 12.8 & 577.2 & Apigenin-rutinoside & $\dagger$ & 269 \\
\hline 13.46 & 447.0 & Luteolin glucoside (2) & $270-340$ & 285 \\
\hline 14.03 & 523.2 & Ligstroside & 282 & $361(100)-291(48)-259(28)$ \\
\hline 14.46 & 447.0 & Luteolin glucoside (3) & $272-328$ & 285 \\
\hline 16.2 & 285.1 & Luteolin & 340 & $285(100)-241(94)-243(62)-217(61)-199(65)-175(52)$ \\
\hline
\end{tabular}

a Numbers in brackets are the relative abundance of listed ions in $\mathrm{MS}^{2}$.

b Identification according to Kontogianni et al. (2013).

Tentatively identified compounds.

† UV data not available because of poor chromatographic resolution or low quantities.

$\mathrm{MS}^{2}$, which are typical $\mathrm{B}$ and $\mathrm{Y}$ ions of a disaccharide with a $[\mathrm{M}-\mathrm{H}]^{-}$of 341 ; the difference between 505 and 341 is 164, which is the molecular mass of coumaric acid. The signal 489 at $5.5 \mathrm{~min}$ produced the 163 fragment in $\mathrm{MS}^{2}$, which could be the $[\mathrm{M}-\mathrm{H}]^{-}$ of coumaric acid. The $[\mathrm{M}-\mathrm{H}]^{-}$of ferulic acid $(\mathrm{m} / \mathrm{z} 193)$ was obtained in $\mathrm{MS}^{2}$ from the parent mass 519 at a retention time of 6.55. The $\lambda_{\max }$ data showed only one maximum value for the peaks at 4.37 and $5.5 \mathrm{~min}$, related to coumaric derivatives; whereas the UV spectra at 6.55 showed two $\lambda_{\max }$ at $292-326 \mathrm{~nm}$, typical of ferulic derivatives. Table 2 reports the quantities of the identified phenolic compounds, expressed as mg of luteolin-7-glucoside per $\mathrm{g}$ of extract. The main compound in the extracts was oleuropein, and hydroxytyrosol glucoside was the main tyrosol-related compound found in the extracts. Regarding flavonoids, we detected luteolin-glucoside isomers. The transition $447 \rightarrow 285$ used to identify luteolin-glucoside was found in three peaks at different retention times, reported as luteolin-glucoside isomers. Moreover, quantitative data showed the high impact of the treatment variable on the concentration of polyphenols; only 10-hydroxyoleuropein and apigenin rutinoside were not significantly influenced. The solvent variable seemed to have a lesser effect, whereas the first order interaction treatment $*$ solvent showed a significant influence for hydroxytyrosol glucoside, tyrosol, secologanoside, 10-hydroxyoleuropein, luteolin-7-glucoside, oleuropein, and luteolin, as well as for total polyphenol content. The results of MANOVA (Table 3 ) also confirmed, with the exception of Pillai's Trace, the significance of the treatment variable on the polyphenol concentration in the extract. Similar results were obtained for the solvent variable and for the first order interaction between variables.

The data (Table 2) showed that polyphenol extraction was significantly more effective on HD leaves, followed by FD and F. Oleuropein was the most abundant single polyphenol compound, in accordance with other authors (Altıok, Bayçın, Bayraktar, \& Ülkü, 2008; Benavente-García et al., 2000; Quirantes-Piné et al., 2012), amounting to as much as $70 \%$ of the extract obtained from HD leaves. Moreover, several of the extracted polyphenols are glycosylated, and the presence of a glucose molecule is likely to influence bioavailability by improving stability and facilitating cell entry (Boss et al., 2016). Hydroxytyrosol glucoside, oleoside, coumaric diglucoside, verbascoside, oleuropein, and ligstroside were detected in larger amounts in HD leaves, than in FD and F, whereas luteolin was found in lower amounts in HD than FD and F. Finally, oleuropein aglycon was detected only in HD leaves, probably because hot air-drying makes it more accessible and easily removable than the other treatments. In addition, considering the total phenols, the data showed a generally positive effect of the ethanol concentration on extraction effectiveness for F and FD leaves. In fact, oleuropein, luteolin glucosides and luteolin values increased together with the ethanol concentration. Different authors have reported that oleuropein and flavonoids are the main components of ethanol extracts, whereas hydroxytyrosol glucoside and phenolic acids are the main components of water extracts (Herrero et al., 2011; Lee et al., 2009; Quirantes-Piné et al., 2012). On the contrary, no significant differences were observed for the HD leaves in relation to the different solvents used for extraction, with the exception of 10-hydroxyoleuropein, highlighting that extraction using only water could give good yields. Overall, the obtained results could be due to inactivation of the enzymes responsible for polyphenol oxidation caused by oven drying temperatures. The lower phenol content of $F$ leaves could be due to their enzymatic oxidation at higher $\mathrm{a}_{\mathrm{w}}$ and to difficulties involved in homogenization and cell wall breakdown (Ahmad-Qasem et al., 2013; OrtegaGarcia, Blanco, Peinado, \& Peragon, 2008). Furthermore, the reason for higher values of antioxidant activity assays and total polyphenol content in HD extracts compared with FD extracts could be that enzymes which became latent during freeze-drying then demonstrated an enhanced oxidative effect during thawing and extraction (Chism \& Haard, 1996). In comparison with the data obtained with HD olive leaves, total polyphenol and oleuropein contents detected in fresh olive fruits were lower (18.71 and $9.09 \mathrm{mg} \mathrm{g}^{-1}$ of fruit extract, respectively), in accordance with Xie et al. (2015) whereas verbascoside ( $7.30 \mathrm{mg} \mathrm{g}^{-1}$ of fruit extract), was the only compound detected in higher amount in green olives than in HD leaf extract. However, it must be considered that degradation and fermentation of polyphenolic compounds are the most important steps in the production of table olives. Their total or partial depletion is fundamental in order to make olives suitable for human consumption. 
Table 2

Relative quantities (means values and standard deviation) of identified or tentatively identified phenolic compounds in olive leaves extracts. Values are expressed as mg g ${ }^{-1}$ extract of luteolin-7-glucoside equivalents.

\begin{tabular}{|c|c|c|c|c|c|c|c|c|c|c|c|c|}
\hline \multirow{2}{*}{ Compounds } & \multirow{2}{*}{$\frac{T}{p \text {-value }}$} & \multirow[t]{2}{*}{$S$} & \multirow[t]{2}{*}{$T^{*} S$} & \multicolumn{3}{|l|}{ Fresh leaves } & \multicolumn{3}{|c|}{ Freeze-dried leaves } & \multicolumn{3}{|c|}{ Hot air-dried leaves } \\
\hline & & & & Eth-0 & Eth-30 & Eth-70 & Eth-0 & Eth-30 & Eth-70 & Eth-0 & Eth-30 & Eth-70 \\
\hline Hydroxytyrosol glucoside & 0.000 & 0.055 & 0.027 & $0.82 \pm 0.05 c^{\mathrm{d}}$ & $1.03 \pm 0.03^{\mathrm{b}}$ & $0.90 \pm 0.03^{\mathrm{bc}}$ & $0.57 \pm 0.08^{\mathrm{e}}$ & $0.63 \pm 0.06^{\mathrm{de}}$ & $0.61 \pm 0.05^{\text {de }}$ & $1.41 \pm 0.03^{\mathrm{a}}$ & $1.35 \pm 0.04^{\mathrm{a}}$ & $1.26 \pm 0.08^{\mathrm{a}}$ \\
\hline Oleoside & 0.000 & 0.075 & 0.223 & $0.08 \pm 0.01^{\mathrm{b}}$ & $0.08 \pm 0.01^{\mathrm{b}}$ & $0.05 \pm 0.02^{\mathrm{b}}$ & $0.10 \pm 0.02^{\mathrm{b}}$ & $0.15 \pm 0.07^{\mathrm{b}}$ & $0.11 \pm 0.00^{\mathrm{b}}$ & $0.46 \pm 0.02^{\mathrm{a}}$ & $0.43 \pm 0.02^{\mathrm{a}}$ & $0.39 \pm 0.01^{\mathrm{a}}$ \\
\hline Tyrosol & 0.054 & 0.01 & 0.036 & $0.01 \pm 0.00^{\mathrm{ab}}$ & $0.01 \pm 0.00^{\mathrm{ab}}$ & $0.01 \pm 0.00^{\mathrm{ab}}$ & $0.01 \pm 0.00^{\mathrm{a}}$ & $0.01 \pm 0.00^{\mathrm{ab}}$ & $0.01 \pm 0.00^{\mathrm{ab}}$ & $0.006 \pm 0.00^{\mathrm{b}}$ & $0.01 \pm 0.00^{\mathrm{ab}}$ & $0.01 \pm 0.00^{\mathrm{ab}}$ \\
\hline Coumaric-diglucoside & 0.000 & 0.581 & 0.182 & $0.01 \pm 0.00^{\mathrm{d}}$ & $0.04 \pm 0.01^{\mathrm{d}}$ & $0.03 \pm 0.00^{\mathrm{d}}$ & $0.11 \pm 0.03^{c}$ & $0.13 \pm 0.04^{\mathrm{c}}$ & $0.14 \pm 0.00^{\mathrm{bc}}$ & $0.23 \pm 0.00^{\mathrm{a}}$ & $0.22 \pm 0.01^{\mathrm{a}}$ & $0.20 \pm 0.00^{\mathrm{ab}}$ \\
\hline Secologanoside & 0.000 & 0.001 & 0.002 & $0.34 \pm 0.09^{\mathrm{bc}}$ & $0.37 \pm 0.10^{\mathrm{bc}}$ & $0.28 \pm 0.16^{c}$ & $0.19 \pm 0.04^{c}$ & $0.81 \pm 0.08^{\mathrm{a}}$ & $0.18 \pm 0.00^{c}$ & $0.81 \pm 0.09^{\mathrm{a}}$ & $0.74 \pm 0.08^{\mathrm{a}}$ & $0.67 \pm 0.05^{\mathrm{ab}}$ \\
\hline Coumaric glucoside & 0.005 & 0.892 & 0.823 & $0.02 \pm 0.01^{\mathrm{a}}$ & $0.02 \pm 0.01^{\mathrm{a}}$ & $0.02 \pm 0.01^{\mathrm{a}}$ & $0.05 \pm 0.04^{\mathrm{a}}$ & $0.05 \pm 0.03^{\mathrm{a}}$ & $0.07 \pm 0.01^{\mathrm{a}}$ & $0.07 \pm 0.01^{\mathrm{a}}$ & $0.07 \pm 0.01^{\mathrm{a}}$ & $0.06 \pm 0.00^{\mathrm{a}}$ \\
\hline Ferulic diglucoside & 0.004 & 0.255 & 0.941 & $0.05 \pm 0.01^{\mathrm{a}}$ & $0.06 \pm 0.01^{\mathrm{a}}$ & $0.05 \pm 0.01^{\mathrm{a}}$ & $0.08 \pm 0.02^{\mathrm{a}}$ & $0.08 \pm 0.00^{\mathrm{a}}$ & $0.07 \pm 0.01^{\mathrm{a}}$ & $0.08 \pm 0.01^{\mathrm{a}}$ & $0.08 \pm 0.01^{\mathrm{a}}$ & $0.07 \pm 0.01^{\mathrm{a}}$ \\
\hline Luteolin diglucoside & 0.001 & 0.009 & 0.374 & $0.01 \pm 0.00^{c}$ & $0.03 \pm 0.01^{\mathrm{abc}}$ & $0.03 \pm 0.01^{\mathrm{abc}}$ & $0.02 \pm 0.01^{\mathrm{bc}}$ & $0.03 \pm 0.01^{\mathrm{abc}}$ & $0.04 \pm 0.00^{\mathrm{ab}}$ & $0.04 \pm 0.00^{\mathrm{ab}}$ & $0.05 \pm 0.00^{\mathrm{a}}$ & $0.05 \pm 0.00^{\mathrm{a}}$ \\
\hline 10-Hydroxyoleuropein & 0.354 & 0.027 & 0.020 & $0.02 \pm 0.01^{\mathrm{b}}$ & $0.04 \pm 0.02^{\mathrm{b}}$ & $0.06 \pm 0.04^{\mathrm{ab}}$ & $0.06 \pm 0.04^{\mathrm{ab}}$ & $0.06 \pm 0.01^{\mathrm{ab}}$ & $0.04 \pm 0.00^{\mathrm{b}}$ & $0.01 \pm 0.00^{\mathrm{b}}$ & $0.02 \pm 0.01^{\mathrm{b}}$ & $0.19 \pm 0.09^{\mathrm{a}}$ \\
\hline Verbascoside & 0.000 & 0.076 & 0.215 & $0.01 \pm 0.00^{\mathrm{b}}$ & $0.05 \pm 0.03^{\mathrm{b}}$ & $0.18 \pm 0.07^{\mathrm{b}}$ & $0.06 \pm 0.05^{\mathrm{b}}$ & $0.34 \pm 0.19^{b}$ & $0.56 \pm 0.02^{\mathrm{ab}}$ & $1.00 \pm 0.21^{\mathrm{a}}$ & $1.05 \pm 0.20^{\mathrm{a}}$ & $0.99 \pm 0.24^{\mathrm{a}}$ \\
\hline Luteolin-7-glucoside (1) & 0.000 & 0.000 & 0.029 & $0.31 \pm 0.15^{\mathrm{e}}$ & $1.29 \pm 0.20^{\mathrm{cd}}$ & $1.54 \pm 0.17^{\mathrm{c}}$ & $1.02 \pm 0.08^{\mathrm{d}}$ & $1.74 \pm 0.18^{\mathrm{abc}}$ & $2.05 \pm 0.01^{\mathrm{ab}}$ & $1.61 \pm 0.08^{\mathrm{bc}}$ & $2.14 \pm 0.02^{\mathrm{a}}$ & $2.15 \pm 0.02^{\mathrm{a}}$ \\
\hline Luteolin-rutinoside & 0.002 & 0.773 & 0.211 & $0.02 \pm 0.01^{\mathrm{b}}$ & $0.11 \pm 0.00^{\mathrm{ab}}$ & $0.08 \pm 0.03^{\mathrm{ab}}$ & $0.22 \pm 0.07^{\mathrm{a}}$ & $0.17 \pm 0.02^{\mathrm{ab}}$ & $0.16 \pm 0.01^{\mathrm{ab}}$ & $0.14 \pm 0.04^{\mathrm{ab}}$ & $0.16 \pm 0.05^{\mathrm{ab}}$ & $0.15 \pm 0.05^{\mathrm{ab}}$ \\
\hline Rutin & 0.008 & 0.155 & 0.457 & $0.03 \pm 0.02^{\mathrm{b}}$ & $0.13 \pm 0.06^{\mathrm{ab}}$ & $0.14 \pm 0.09^{\mathrm{ab}}$ & $0.19 \pm 0.05^{\mathrm{ab}}$ & $0.20 \pm 0.19^{\mathrm{ab}}$ & $0.39 \pm 0.06^{\mathrm{a}}$ & $0.28 \pm 0.07^{\mathrm{ab}}$ & $0.30 \pm 0.07^{\mathrm{ab}}$ & $0.29 \pm 0.06^{\mathrm{ab}}$ \\
\hline Oleuropein & 0.000 & 0.000 & 0.000 & $0.04 \pm 0.01^{\mathrm{c}}$ & $0.51 \pm 0.12^{\mathrm{c}}$ & $1.69 \pm 0.15^{\mathrm{c}}$ & $0.50 \pm 0.06^{c}$ & $1.83 \pm 0.11^{\mathrm{c}}$ & $7.36 \pm 0.22^{\mathrm{b}}$ & $22.39 \pm 0.98^{\mathrm{a}}$ & $22.42 \pm 0.88^{\mathrm{a}}$ & $21.31 \pm 0.53^{\mathrm{a}}$ \\
\hline Oleuropein aglycon & - & - & - & nd & nd & nd & nd & nd & nd & $0.03 \pm 0.00$ & $0.03 \pm 0.00$ & $0.03 \pm 0.00$ \\
\hline Apigenin rutinoside & 0.242 & 0.407 & 0.811 & $0.10 \pm 0.03^{\mathrm{a}}$ & $0.13 \pm 0.03^{\mathrm{a}}$ & $0.13 \pm 0.05^{\mathrm{a}}$ & $0.15 \pm 0.04^{\mathrm{a}}$ & $0.17 \pm 0.07^{\mathrm{a}}$ & $0.12 \pm 0.00^{\mathrm{a}}$ & $0.09 \pm 0.02^{\mathrm{a}}$ & $0.06 \pm 0.06^{\mathrm{a}}$ & $0.10 \pm 0.04^{\mathrm{a}}$ \\
\hline Luteolin glucoside (2) & 0.023 & 0.000 & 0.438 & $0.15 \pm 0.05^{\mathrm{d}}$ & $0.51 \pm 0.07^{\mathrm{abc}}$ & $0.6 \pm 0.12^{\mathrm{ab}}$ & $0.27 \pm 0.10^{\mathrm{cd}}$ & $0.58 \pm 0.16^{\mathrm{abc}}$ & $0.74 \pm 0.01^{\mathrm{a}}$ & $0.40 \pm 0.02^{\mathrm{bcd}}$ & $0.66 \pm 0.01^{\mathrm{ab}}$ & $0.67 \pm 0.01^{\mathrm{ab}}$ \\
\hline Ligstroside & 0.000 & 0.632 & 0.660 & $0.01 \pm 0.01^{\mathrm{b}}$ & $0.02 \pm 0.01^{\mathrm{b}}$ & $0.11 \pm 0.01^{\mathrm{b}}$ & $0.01 \pm 0.00^{\mathrm{b}}$ & $0.06 \pm 0.02^{\mathrm{b}}$ & $0.15 \pm 0.00^{\mathrm{b}}$ & $0.80 \pm 0.18^{\mathrm{a}}$ & $0.80 \pm 0.18^{\mathrm{a}}$ & $0.74 \pm 0.18^{\mathrm{a}}$ \\
\hline Luteolin glucoside (3) & 0.048 & 0.000 & 0.711 & $0.03 \pm 0.01^{\mathrm{d}}$ & $0.11 \pm 0.01^{\mathrm{abc}}$ & $0.13 \pm 0.00^{\mathrm{ab}}$ & $0.05 \pm 0.03^{\mathrm{cd}}$ & $0.12 \pm 0.05^{\mathrm{abc}}$ & $0.16 \pm 0.00^{\mathrm{a}}$ & $0.08 \pm 0.00^{\mathrm{bcd}}$ & $0.14 \pm 0.00^{\mathrm{ab}}$ & $0.15 \pm 0.01^{\mathrm{ab}}$ \\
\hline Luteolin & 0.000 & 0.000 & 0.001 & $0.14 \pm 0.01^{\mathrm{de}}$ & $0.58 \pm 0.12^{\mathrm{bc}}$ & $0.34 \pm 0.15^{\text {cde }}$ & $0.44 \pm 0.15^{\mathrm{cd}}$ & $0.81 \pm 0.08^{\mathrm{b}}$ & $1.18 \pm 0.04^{\mathrm{a}}$ & $0.05 \pm 0.03^{\mathrm{e}}$ & $0.15 \pm 0.04^{\mathrm{de}}$ & $0.04 \pm 0.00^{\mathrm{e}}$ \\
\hline Total polyphenols & 0.000 & 0.000 & 0.000 & $2.19 \pm 0.36^{\mathrm{e}}$ & $5.10 \pm 0.68^{\mathrm{d}}$ & $6.38 \pm 0.49^{\mathrm{cd}}$ & $4.08 \pm 0.59^{\mathrm{de}}$ & $7.97 \pm 0.89^{c}$ & $14.12 \pm 0.24^{\mathrm{b}}$ & $30.01 \pm 0.74^{\mathrm{a}}$ & $30.88 \pm 0.68^{\mathrm{a}}$ & $29.51 \pm 0.10^{\mathrm{a}}$ \\
\hline
\end{tabular}

$T$, treatment variable; $S$, solvent variable; Eth-0, only water Milli- $Q^{\circledast}$; Eth-30, ethanol/water 30:70 (v/v); Eth-70, ethanol/water 70:0 (v/v); nd, not detected.

Values highlighted in bold indicate a significant influence of the considered variable or the first order interaction.

Different letters in row indicate a significant differences at $p<0.05$ determined by ANOVA. 
Table 3

Results of multivariate analysis of variance (MANOVA).

\begin{tabular}{|c|c|c|c|c|c|c|}
\hline Effect & & Value & $\mathrm{F}$ & Hypothesis df & Error df & $p$-value \\
\hline \multirow[t]{3}{*}{ Intercept } & Pillai's Trace & 1.000 & 813.440 & 6 & 1 & 0.027 \\
\hline & Wilks' Lambda & 0.000 & 813.440 & 6 & 1 & 0.027 \\
\hline & Roy's Largest Root & 4880.641 & 813.440 & 6 & 1 & 0.027 \\
\hline \multirow{3}{*}{ Treatment } & Pillai's Trace & 1.880 & 5.216 & 12 & 4 & 0.062 \\
\hline & Wilks' Lambda & 0.000 & 82.886 & 12 & 2 & 0.012 \\
\hline & Roy's Largest Root & 29821.905 & 9940.635 & 6 & 2 & 0.000 \\
\hline \multirow{3}{*}{ Solvent } & Pillai's Trace & 1.835 & 3.698 & 12 & 4 & 0.109 \\
\hline & Wilks' Lambda & 0.000 & 16.649 & 12 & 2 & 0.058 \\
\hline & Roy's Largest Root & 1676.397 & 558.799 & 6 & 2 & 0.002 \\
\hline \multirow[t]{3}{*}{ Treatment * solvent } & Pillai's Trace & 2.580 & 1.211 & 24 & 16 & 0.352 \\
\hline & Wilks' Lambda & 0.000 & 6.915 & 24 & 5 & 0.024 \\
\hline & Roy's Largest Root & 1893.161 & 1262.107 & 6 & 4 & 0.000 \\
\hline
\end{tabular}

Table 4

Results of TPC (total phenol content) and of antioxidant activity assays (means values and standard deviation), together with the results of the two-way ANOVA.

\begin{tabular}{|c|c|c|c|c|c|c|c|c|c|c|c|c|}
\hline & $T$ & $S$ & $T^{*} S$ & \multicolumn{3}{|c|}{ Fresh leaves } & \multicolumn{3}{|c|}{ Freeze-dried leaves } & \multicolumn{3}{|c|}{ Hot air-dried leaves } \\
\hline & $p$-value & & & Eth-0 & Eth-30 & Eth-70 & Eth-0 & Eth-30 & Eth-70 & Eth-0 & Eth-30 & Eth-70 \\
\hline TPC (mg GAE g $\left.{ }^{-1}\right)$ & 0.000 & 0.000 & 0.000 & $41 \pm 1^{\mathrm{f}}$ & $70 \pm 3^{e}$ & $67 \pm 2^{\mathrm{e}}$ & $79 \pm 2^{d}$ & $110 \pm 2^{\mathrm{c}}$ & $108 \pm 2^{\mathrm{c}}$ & $144 \pm 1^{\mathrm{b}}$ & $151 \pm 1^{\mathrm{a}}$ & $139 \pm 2^{b}$ \\
\hline 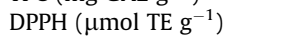 & 0.000 & 0.000 & 0.000 & $277 \pm 2^{g}$ & $427 \pm 2^{f}$ & $427 \pm 1^{\mathrm{f}}$ & $545 \pm 4^{\mathrm{e}}$ & $704 \pm 5^{c}$ & $641 \pm 5^{d}$ & $890 \pm 3^{b}$ & $922 \pm 2^{\mathrm{a}}$ & $881 \pm 4^{\mathrm{b}}$ \\
\hline ABTS-TEAC $\left(\mu \mathrm{mol} \mathrm{TE} \mathrm{g}^{-1}\right)$ & 0.000 & 0.000 & 0.000 & $385 \pm 2^{\mathrm{i}}$ & $524 \pm 1^{\mathrm{f}}$ & $472 \pm 1^{\mathrm{h}}$ & $482 \pm 1^{\mathrm{g}}$ & $627 \pm 3^{d}$ & $602 \pm 5^{e}$ & $894 \pm 3^{b}$ & $908 \pm 2^{a}$ & $850 \pm 2^{c}$ \\
\hline
\end{tabular}

$T$, treatment variable; $S$, solvent variable; Eth-0, sole water Milli-Q ${ }^{\circledR}$; Eth-30, ethanol/water 30:70 (v/v); Eth-70, ethanol/water 70:0 (v/v).

Values highlighted in bold indicate a significant influence of the considered variable or first order interaction.

Different letters in row indicate a significant differences at $p<0.05$ determined by ANOVA.

Table 5

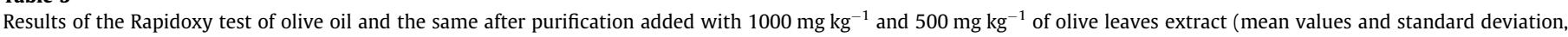
min, together with the results of the two-way ANOVA).

\begin{tabular}{|c|c|c|c|c|c|c|c|c|c|c|c|}
\hline \multirow[t]{2}{*}{ Samples } & $T$ & $S$ & $C$ & \multirow{2}{*}{$\begin{array}{l}\text { Extract added } \\
\left(\mathrm{mg} \mathrm{kg}^{-1}\right)\end{array}$} & \multirow[t]{2}{*}{ Control } & \multicolumn{3}{|c|}{ Freeze-dried leaves } & \multicolumn{3}{|c|}{ Hot air-dried leaves } \\
\hline & $p$-value & & & & & Eth-0 & Eth-30 & Eth-70 & Eth-0 & Eth-30 & Eth-70 \\
\hline Olive oil & 0.000 & 0.000 & 0.000 & $\begin{array}{l}1000 \\
500\end{array}$ & $62.7 \pm 1.6$ & $\begin{array}{l}67.7 \pm 0.1^{\mathrm{ef}^{* *}} \\
65.1 \pm 0.4^{\mathrm{f}}\end{array}$ & $\begin{array}{l}70.2 \pm 0.5^{\text {cde }^{* * *}} \\
64.4 \pm 0.7^{f}\end{array}$ & $\begin{array}{l}73.0 \pm 1.0^{\mathrm{bcd}^{* * *}} \\
64.9 \pm 0.1^{\mathrm{f}}\end{array}$ & $\begin{array}{l}74.8 \pm 1.0^{\mathrm{bc}^{* * *}} \\
67.2 \pm 1.7^{\mathrm{ef}^{*}}\end{array}$ & $\begin{array}{l}75.8 \pm 1.4^{\mathrm{b}^{* * *}} \\
68.0 \pm 1.5^{\mathrm{ef}^{* *}}\end{array}$ & $\begin{array}{l}83.3 \pm 2.5^{\mathrm{a}^{* * *}} \\
69.1 \pm 0.5^{\mathrm{def}^{* *}}\end{array}$ \\
\hline $\begin{array}{l}\text { Purified } \\
\text { olive oil }\end{array}$ & 0.000 & 0.000 & 0.000 & $\begin{array}{l}1000 \\
500\end{array}$ & $28.6 \pm 1.4$ & $\begin{array}{l}38.4 \pm 1.2^{\mathrm{efg}^{* * *}} \\
33.2 \pm 0.5^{\mathrm{h}^{*}}\end{array}$ & $\begin{array}{l}42.1 \pm 1.6^{\mathrm{cde}^{* * *}} \\
36.6 \pm 1.6^{\mathrm{fgh}^{* *}}\end{array}$ & $\begin{array}{l}45.9 \pm 2.3^{\mathrm{abc}^{* * *}} \\
35.2 \pm 1.4^{\mathrm{gh}^{* *}}\end{array}$ & $\begin{array}{l}44.6 \pm 0.4^{\mathrm{bcd}^{* * *}} \\
34.0 \pm 0.3^{\mathrm{gh}^{*}}\end{array}$ & $\begin{array}{l}49.9 \pm 0.3^{\mathrm{a}^{* * *}} \\
40.5 \pm 1.3^{\mathrm{de}^{* * *}}\end{array}$ & $\begin{array}{l}49.3 \pm 1.0^{\mathrm{ab}^{* * *}} \\
35.9 \pm 0.8^{\mathrm{fgh}^{* *}}\end{array}$ \\
\hline
\end{tabular}

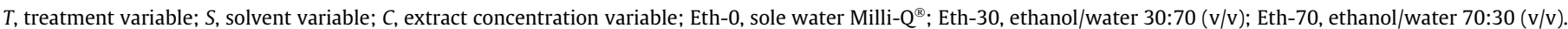
Values highlighted in bold indicate a significant influence of the considered variable or first order interaction.

Different letters in row indicate a significant differences at $p<0.05$ determined by ANOVA.

$(p<0.05),{ }^{* *}(p<0.01),{ }^{* * *}(p<0.001)$ : results of Dunnett test than control.

Then, the polyphenol compounds of processed table olives, including oleuropein, are lower than those of fresh olives, since they are hydrolyzed and/or lost during de-bittering treatment (Iorizzo et al., 2016). Moreover, the antioxidant activity of the lyophilized extract obtained from fruits, determined by DPPH and ABTS-TEAC, was lower than that of leaves, with values equal to 600.80 and $554.78 \mu \mathrm{mol} \mathrm{TE} \mathrm{g}^{-1}$ of extract, respectively.

Table 4 reports the total phenolic contents of the extracts, determined by Folin-Ciocalteu assay, antioxidant activity assessed by DPPH and ABTS tests, and the results of two-way ANOVA. Both independent variables, and their interaction, showed a highly significant effect $(p<0.001)$, indicating that both dehydration treatment and extraction solvent affected the antioxidant activity of the extracts.

Irrespective of the extraction solvent used, the effects of the dehydration treatment was as follows: HD > FD > F. Similar results were found by other authors (Ahmad-Qasem et al., 2013), even when using different plant materials for the extraction of bioactive compounds (Hossain, Barry-Ryan, Martin-Diana, \& Brunton, 2010).

As regards the extraction solvent used, the highest levels of antioxidant activity were observed in Eth-30 extracts. In HD extracts, the observed differences were significant for all three indices, in FD extracts only for DPPH and ABTS assays, and in F extracts only for ABTS. On the other hand, Altiok et al. (2008) found higher total polyphenols and\% inhibition of the ABTS radical cation when ethanol in the mixture was increased. Finally, extraction from HD leaves using only water (Eth-0) gave comparable results to other solvents, whereas for F and FD leaves the values obtained for different parameters were dramatically lower than those obtained using a mixture containing more ethanol.

Table 5 reports the data of the antioxidant activity of the extracts on olive oil and on purified olive oil, together with the results of two-way ANOVA. F extracts were not considered, due to their lower extraction yield and antioxidant activity. The effectiveness of the extracts in oils was also affected by both independent variables, although all extracts were effective in increasing the induction time of both olive oil and purified olive oil, with the exception of FD extracts on olive oil, confirming the results observed in DPPH and ABTS assays. Moreover, induction time increased when the amount of added extract increased. HD extracts were the most effective and observed effectiveness for the extraction solvent was Eth-70 > Eth-30 > Eth-0, although in most cases there was no statistical significance. 


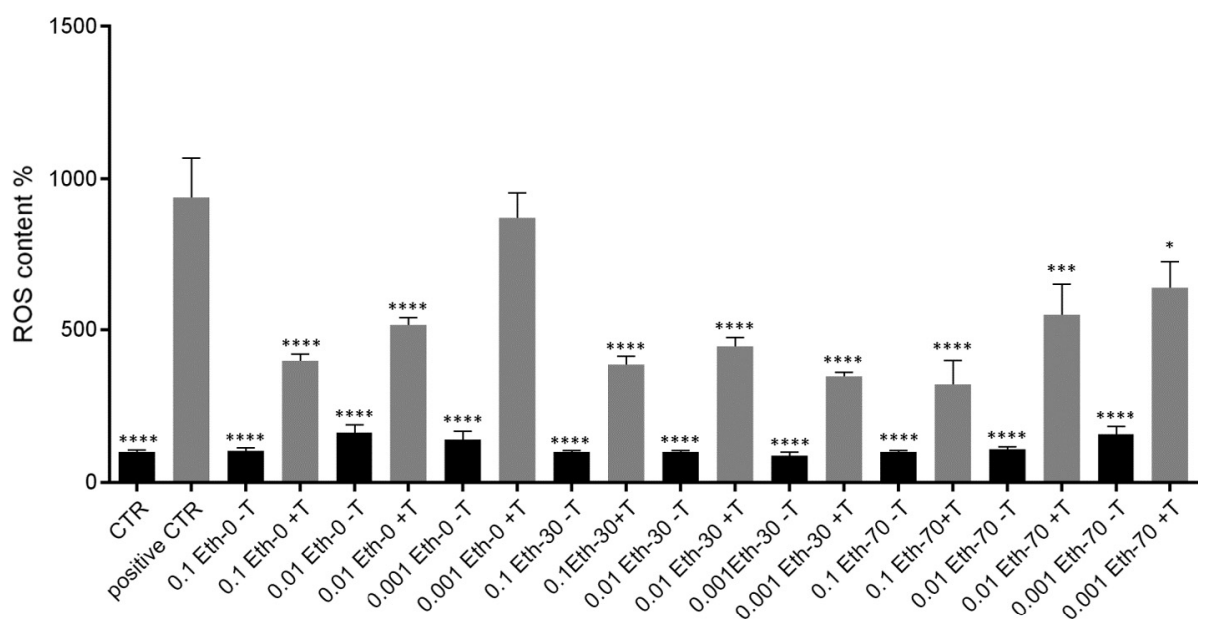

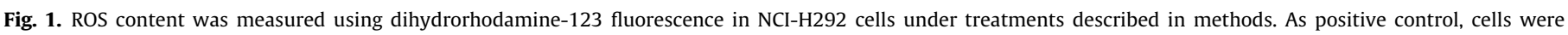

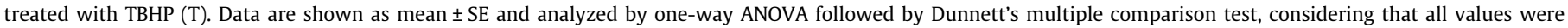
compared to the positive control with ${ }^{*} p<0.05,{ }^{* *} p<0.01,{ }^{* * *} p<0.001$, and ${ }^{* * * *} p<0.0001$.

\subsection{Antioxidant activity in biological systems}

Reactive Oxygen Species contribute to and promote/amplify several human diseases such as asthma and COPD (Kirkham \& Rahman, 2006). There is much evidence to associate a diet containing plenty of fruit, vegetables, and olive oil, containing high levels of phenolic compounds, with a low incidence of chronic inflammation disorders and cardiovascular disease (Perez-Martinez et al., 2007). Here, we evaluate the potential antioxidant efficacy of HD olive leaf extracts via in vitro experiments using bronchial epithelial NCI-H292 cells. Cells were treated as described in the Methods section, and ROS content was measured by using a dihydrorhodamine-123 based method. The data summarized in Fig. 1 show that compared to positive control cells treated with the oxidant TBHP, incubation with olive leaf extracts $(0.1$; $0.01 \mathrm{mg} \mathrm{mL}^{-1}$ ) obtained without ethanol (Eth-0) significantly decreased intracellular ROS content produced by the oxidant TBHP. Similarly, incubation with the extracts $\left(0.1 ; 0.01 ; 0.001 \mathrm{mg} \mathrm{mL}^{-1}\right)$ obtained with ethanol (Eth-30 and Eth-70) reduced the increase in ROS content induced by TBHP. Together, these findings strongly suggest that olive leaf extracts displayed significant antioxidant activity in a lung cell model used to study chronic inflammatory diseases such as asthma and COPD (Lee et al., 2016). Other phyto-compounds have already been tested for their ability to reduce the symptoms of several lung diseases. One of these, theophylline, is actually used to treat asthma in developing countries due to its effectiveness and long-acting cheaper preparation (Evans et al., 1997), although several side-effects associated with theophylline treatment have been described. (Celis \& Rada, 2015).

In the present study, we found that olive leaf extracts displayed a good antioxidant activity. Specifically, the mixture obtained without ethanol displayed an optimal physiological response, since it significantly reduced intracellular ROS content. This was similar to the effects observed when using the other technical approaches and including ethanol, showing that without ethanol it is still possible to isolate and obtain an enriched antioxidant compound mixture. Lung diseases such as COPD are expected to become the world's third leading cause of death by the year 2030 (Nofziger, Dossena, Suzuki, Izuhara, \& Paulmichl, 2011), probably due to increases in environmental pollution. Given this scenario, there is an unmet need for improved understanding of the possible use of "green extracted" olive leaf compounds, in order to identify new and promising therapeutical targets.

\section{Conclusions}

This study demonstrated the effect of leaf pre-treatment on both polyphenol content and antioxidant activity, whereas the solvent used seemed to have a lesser effect. In particular, the best results were obtained with hot air-dried leaves and ethanol/water (30:70, v/v) as the extraction solvent. Water used as an extraction solvent gave comparable extraction yields to other mixtures only for hot air-dried leaves. The antioxidant compounds exerted a significant antioxidant activity on vegetable oils (increasing the induction time of the olive oil and of the purified olive oil of about $24 \%$ and $66 \%$, respectively) and lung cells (decreasing the ROS content of about $40 \%$ ).

\section{Conflict of interests}

The authors declare that there is no conflict of interests regarding the publication of this paper.

\section{Acknowledgements}

This work has been supported by AGER 2 Project, grant no. 2016-0105.

\section{References}

Abaza, L., Talorete, T. P. N., Yamada, P., Kurita, Y., Zarrouk, M., \& Isoda, H. (2007). Induction of growth inhibition and differentiation of human leukemia HL-60 cells by a Tunisian Gerboui olive leaf extract. Bioscience, Biotechnology $\mathcal{E}^{\prime}$ Biochemistry, 71, 1306-1312.

Ahmad-Qasem, M., Barrajón-Catalán, E., Micol, V., Mulet, A., \& García-Pérez, J. (2013). Influence of freezing and dehydration of olive leaves (var. Serrana) on extract composition and antioxidant potential. Food Research International, 50, 189-196.

Ahmad-Qasem, M., Cánovas, J., Barrajón-Catalán, E., Micol, V., Cárcel, J., \& GarcíaPérez, J. (2013). Kinetic and compositional study of phenolic extraction from olive leaves (var. Serrana) by using power ultrasound. Innovative Food Science \& Emerging Technologies, 17, 120-129.

Altıok, E., Bayçı, D., Bayraktar, O., \& Ülkü, S. (2008). Isolation of polyphenols from the extracts of olive leaves (Olea europaea L.) by adsorption on silk fibroin. Separation and Purification Technology, 62, 342-348.

Bassani, B. Rossi, T . De Stefano, D. Pizzichini, D Corradino, P. Macrì, N ... Bruno, A (2016). Potential chemopreventive activities of a polyphenol rich purified extract from olive mill wastewater on colon cancer cells. Journal of Functional Foods, 27, 236-248.

Benavente-García, O., Castillo, J., Lorente, J., Ortuño, A., \& Del Rio, J. A. (2000). Antioxidant activity of phenolics extracted from Olea europaea L. leaves. Food Chemistry, 68, 457-462. 
Boss, A., Bishop, K. S., Marlow, G., Barnett, M. P., \& Ferguson, L. R. (2016). Evidence to support the anti-cancer effect of olive leaf extract and future Directions. Nutrients, 8. 513-(1-22).

Brand-Williams, W., Cuvelier, M. E., \& Berset, C. L. W. T. (1995). Use of a free radical method to evaluate antioxidant activity. LWT-Food Science and Technology, 28, 25-30.

Capello, C., Fischer, U., \& Hungerbühler, K. (2007). What is a green solvent? A comprehensive framework for the environmental assessment of solvents. Green Chemistry, 9, 927-934.

Castillo, J. J., Alcaraz, M., \& Benavente-García, O. (2010). Antioxidant and radioprotective effects of olive leaf extract. In V. R. Preedy \& R. R. Watson (Eds.), Olives and olive oil in health and disease prevention (pp. 951-958). Oxford: Academic Press.

Celis, P., \& Rada, G. (2015). High-dose inhaled corticosteroids or addition of theophylline in patients with poorly controlled asthma? Medwave, 15. 62246224.

Chism, G. W., \& Haard, N. F. (1996). Characteristics of edible plant tissues. In O. R. Fennema (Ed.), Food chemistry (pp. 943-1011). New York: Marcel Dekker Inc..

de Bock, M., Derraik, J. G., Brennan, C. M., Biggs, J. B., Morgan, P. E., Hodgkinson, S. C., ... Cutfield, W. S. (2013). Olive (Olea europaea L.) leaf polyphenols improve insulin sensitivity in middle-aged overweight men: A randomized, placebocontrolled, crossover trial. PLoS ONE, 8, e57622.

Erbay, Z., \& Icier, F. (2010). The importance and potential uses of olive leaves. Food Reviews International, 26, 319-334.

Evans, D. J., Taylor, D. A., Zetterstrom, O., Chung, K. F., O’Connor, B. J., \& Barnes, P. J. (1997). A comparison of low-dose inhaled budesonide plus theophylline and high-dose inhaled budesonide for moderate asthma. The New England Journal of Medicine, 337, 1412-1419.

Food and agriculture organization of the United Nations - Statistic Division (2016). <http://faostat3.fao.org/browse/Q/QC/E/> Accessed 05.04.2016.

Fu, S., Arráez-Roman, D., Segura-Carretero, A., Menéndez, J. A., Menéndez-Gutiérrez, M. P., Micol, V., \& Fernández-Gutiérrez, A. (2010). Qualitative screening of phenolic compounds in olive leaf extracts by hyphenated liquid chromatography and preliminary evaluation of cytotoxic activity against human breast cancer cells. Analytical and Bioanalytical Chemistry, 397, 643-654.

Ghoreishi, S. M., \& Shahrestani, R. G. (2009). Subcritical water extraction of mannitol from olive leaves. Journal of Food Engineering, 93, 474-481.

Hayes, J. E., Stepanyan, V., Allen, P., O'Grady, M. N., \& Kerry, J. P. (2010). Effect of lutein, sesamol, ellagic acid and olive leaf extract on the quality and shelf-life stability of packaged raw minced beef patties. Meat Science, 84, 613-620.

Herrero, M., Temirzoda, T. N., Segura-Carretero, A., Quirantes, R., Plaza, M., \& Ibañez, E. (2011). New possibilities for the valorization of olive oil by-products. Journal of Chromatography A, 1218, 7511-7520.

Hossain, M., Barry-Ryan, C., Martin-Diana, A., \& Brunton, N. (2010). Effect of drying method on the antioxidant capacity of six Lamiaceae herbs. Food Chemistry, 123, 85-91.

Huang, W., Xue, A., Niu, H., Jia, Z., \& Wang, J. (2009). Optimised ultrasonic-assisted extraction of flavonoids from Folium eucommiae and evaluation of antioxidant activity in multi-test systems in vitro. Food Chemistry, 114, 1147-1154.

Iorizzo, M., Lombardi, S. J., Macciola, V., Testa, B., Lustrato, G., Lopez, F., \& De Leonardis, A. (2016). Technological potential of lactobacillus strains isolated from fermented green olives: In vitro studies with emphasis on oleuropeindegrading capability. The Scientific World Journal. http://dx.doi.org/10.1155/ 2016/1917592.

Japón-Luján, R., Luque-Rodríguez, J. M., \& Luque de Castro, M. D. (2006). Dynamic ultrasound-assisted extraction of oleuropein and related biophenols from olive leaves. Journal of Chromatography. A, 1108, 76-82.

Ju, Z., \& Howard, L. R. (2005). Subcritical water and sulfured water extraction of anthocyanins and other phenolics from dried red grape skin. Journal of Food Science, 70, 270-276.

Kirkham, P., \& Rahman, I. (2006). Oxidative stress in asthma and COPD: Antioxidants as a therapeutic strategy. Pharmacology \& Therapeutics, 111, 476-494.

Kontogianni, V. G., Charisiadis, P., Margianni, E., Lamari, F. N., Gerothanassis, I. P., \& Tzakos, A. G. (2013). Olive leaf extracts are a natural source of advanced glycation end product inhibitors. Journal of Medicinal Food, 16, 817-822.

Le Floch, F., Tena, M., Ríos, A., \& Valcárcel, M. (1998). Supercritical fluid extraction of phenol compounds from olive leaves. Talanta, 46, 1123-1130.

Lee, O. H., Lee, B. Y., Lee, J., Lee, H. B., Son, J. Y., Park, C. S., ... Kim, Y. C. (2009). Assessment of phenolics-enriched extract and fractions of olive leaves and their antioxidant activities. Bioresource Technology, 100, 6107-6113.

Lee, S., Sung, M., Ryu, H., Lee, J., Kim, H., In, H., ... Oh, S. (2016). Verproside inhibits TNF- $\alpha$-induced MUC5AC expression through suppression of the TNF- $\alpha / N F-\kappa B$ pathway in human airway epithelial cells. Cytokine, 77, 168-175.

Lee, I., \& Yang, C. (2012). Role of NADPH oxidase/ROS in pro-inflammatory mediators-induced airway and pulmonary diseases. Biochemical Pharmacology, $84,581-590$.

Nofziger, C., Dossena, S., Suzuki, S., Izuhara, K., \& Paulmichl, M. (2011). Pendrin function in airway epithelia. Cellular Physiology and Biochemistry, 28, 571-578.

Ortega-Garcia, F., Blanco, S., Peinado, M., \& Peragon, J. (2008). Polyphenol oxidase and its relationship with oleuropein concentration in fruits and leaves of olive
(Olea europaea) cv. 'Picual' trees during fruit ripening. Tree Physiology, 28, 45-54.

Paradiso, V., Clemente, A., Summo, C., Pasqualone, A., \& Caponio, F. (2016). Towards green analysis of virgin olive oil phenolic compounds: Extraction by a natural deep eutectic solvent and direct spectrophotometric detection. Food Chemistry, $212,43-47$.

Paradiso, V., Gomes, T., Nasti, R., Caponio, F., \& Summo, C. (2010). Effects of free fatty acids on the oxidative processes in purified olive oil. Food Research International, 43, 1389-1394.

Perez-Martinez, P., Lopez-Miranda, J., Blanco-Colio, L., Bellido, C., Jimenez, Y. Moreno, J., ... Perez-Jimenez, F. (2007). The chronic intake of a Mediterranean diet enriched in virgin olive oil, decreases nuclear transcription factor $\mathrm{\kappa B}$ activation in peripheral blood mononuclear cells from healthy men. Atherosclerosis, 194, 141-146.

Quirantes-Piné, R., Lozano-Sánchez, J., Herrero, M., Ibáñez, E., Segura-Carretero, A., \& Fernández-Gutiérrez, A. (2012). HPLC-ESI-QTOF-MS as a powerful analytical tool for characterising phenolic compounds in olive-leaf extracts. Phytochemical Analysis, 24, 213-223.

Rahmanian, N., Jafari, S., \& Wani, T. (2015). Bioactive profile, dehydration, extraction and application of the bioactive components of olive leaves. Trends in Food Science \& Technology, 42, 150-172.

Re, R., Pellegrini, N., Proteggente, A., Pannala, A., Yang, M., \& Rice-Evans, C. (1999). Antioxidant activity applying an improved ABTS radical cation decolorization assay. Free Radical Biology and Medicine, 26, 1231-1237.

Rombaut, N., Tixier, A., Bily, A., \& Chemat, F. (2014). Green extraction processes of natural products as tools for biorefinery. Biofuels, Bioproduct E Biorefining, 8, 530-544.

Samet, I., Han, J., Jlaiel, L., Sayadi, S., \& Isoda, H. (2014). Olive (Olea europaea) leaf extract induces apoptosis andmonocyte/macrophage differentiation in human chronicmye-logenous leukemia K562 cells: Insight into the underlying mechanism. Oxidative Medicine and Cellular Longevity. http://dx.doi.org/ $10.1155 / 2014 / 927619$.

Sánchez-Ávila, N., Priego-Capote, F., Ruiz-Jiménez, J., \& de Castro, L. M. D. (2009). Fast and selective determination of triterpenic compounds in olive leaves by liquid chromatography-tandem mass spectrometry with multiple reaction monitoring after microwave-assisted extraction. Talanta, 78, 40-48.

Sato, H., Genet, C., Strehle, A., Thomas, C., Lobstein, A., Wagner, A., ... Saladin, R. (2007). Anti-hyperglycemic activity of a TGR5 agonist isolated from Olea europaea. Biochemical and Biophysical Research Communications, 362, 793-798.

Shalmashi, A. Abedi, M. Golmohammad, F. \& Eikani, M. H. (2010). Isolation of caffeine from tea waste using subcritical water extraction. Journal of Food Process Engineering, 33, 701-711.

Taamalli, A., Arráez-Román, D., Barrajón-Catalán, E., Ruiz-Torres, V., Pérez-Sánchez, A., Herrero, M., \& Fernández-Gutiérrez, A. (2012). Use of advanced techniques for the extraction of phenolic compounds from Tunisian olive leaves: phenolic composition and cytotoxicity against human breast cancer cells. Food and Chemical Toxicology, 50, 1817-1825.

Taamalli, A., Arráez-Román, D., Ibañez, E., Zarrouk, M., Segura-Carretero, A., \& Fernández- Gutiérrez, A. (2012). Optimization of microwave-assisted extraction for the characterization of olive leaf phenolic compounds by using HPLC-ESITOF-MS/IT-MS2. Journal of Agricultural and Food Chemistry, 60, 791-798.

Tamma, G., Ranieri, M., Di Mise, A., Centrone, M., Svelto, M., \& Valenti, G. (2014). Glutathionylation of the aquaporin-2 water channel. Journal of Biological Chemistry, 289, 27807-27813.

Tamma, G., \& Valenti, G. (2016). Evaluating the oxidative stress in renal diseases: What is the role for s-glutathionylation? Antioxidants \& Redox Signaling, 25 $147-164$.

Tavafi, M., Ahmadvand, H., \& Toolabi, P. (2012). Inhibitory effect of olive leaf extract on gentamicin-induced nephrotoxicity in rats. Kidney Diseases, 6, 25-32.

van der Stelt, I., Hoek-van den Hil, E. F., Swarts, H. J., Vervoort, J. J., Hoving, L., Skaltsounis, L., ... Keijer, J. (2015). Nutraceutical oleuropein supplementation prevents high fat diet-induced adiposity in mice. Journal of Functional Foods, 14, $702-715$.

Vilkhu, K., Mawson, R., Simons, L., \& Bates, D. (2008). Applications and opportunities for ultrasound assisted extraction in the food industry - A review. Innovative Food Science E' Emerging Technologies, 9, 161-169.

Wang, L., \& Weller, C. (2006). Recent advances in extraction of nutraceuticals from plants. Trends in Food Science \& Technology, 17, 300-312.

Xie, P. J., Huang, L. X., Zhang, C. H., \& Zhang, Y. L. (2015). Phenolic compositions, and antioxidant performance of olive leaf and fruit (Olea europaea L.) extracts and their structure-activity relationships. Journal of Functional Foods, 16, 460-471.

Zhang, H., Yang, X., \& Wang, Y. (2011). Microwave assisted extraction of secondary metabolites from plants: Current status and future directions. Trends in Food Science \& Technology, 22, 672-688.

Zhang, H. F., Yang, X. H., Zhao, L. D., \& Wang, Y. (2009). Ultrasonic-assisted extraction of epimedin $\mathrm{C}$ from fresh leaves of Epimedium and extraction mechanism. Innovative Food Science E' Emerging Technologies, 10, 54-60.

Zulueta, A., Esteve, M., \& Frígola, A. (2009). ORAC and TEAC assays comparison to measure the antioxidant capacity of food products. Food Chemistry, 114 310-316. 